\title{
Boundary Crossing during Pre-service Teacher Training: empowering or hampering professional growth?
}

\author{
Christine Harrison ${ }^{1}$ (D)
}

Received: 23 March 2017/Accepted: 30 March 2017/Published online: 4 October 2017

(C) The Author(s) 2017. This article is an open access publication

\begin{abstract}
Yuli Rahmawati's paper presents an auto-ethnographic inquiry into her lived experiences as a science teacher in different countries. Through her reflections and analysis of events, Yuli captures and builds a model of her identity and explores the influence of inter- and intra-cultural perspectives in shaping how she recognizes herself and brings meaning to her professional life. Yuli's insights and explanations of teaching within different cultural contexts highlight the importance of personally relevant and meaningful knowledge, where expectations and accepted norms, that might fit well within one community, may be seen quite differently in another. While for Yuli, this led to professional growth as she inquired and made sense of her new context, my concern is that the social and cultural change could, in some instances, lead to disengagement rather than professional growth. My concern is that the conflict that arises from boundary crossing may be experienced even stronger by inexperienced professionals, such as pre-service teachers. The learning trajectory of pre-service teachers is steep; they need to gain stronger knowledge of curriculum and pedagogy and an awareness of how their students learn. They also need to build confidence in their professional self and what they can do to support and trigger student learning. For this to happen, in the tight time frames available on teacher education courses, pre-service teachers need to understand and engage with the new community that they are placed in very quickly, to make sense of both their role and that of others within the community. This paper suggests that pre-service providers should carefully consider the learning opportunities offered by school contexts, that may vary
\end{abstract}

Lead Editor: M. Reiss.

This is a response to Y. Rahmawati and P. Taylor "The fish becomes aware of the water in which it swims": revealing the power of culture in shaping teaching identity. doi:10.1007/s11422-016-9801-1.

Christine Harrison

christine.harrison@kcl.ac.uk

1 King's College, London, UK 
dramatically from the social and cultural contexts experienced by their teachers as part of their own education, to prevent disengagement or misunderstanding hampering professional growth.

Keywords Pre-service - Identity · Boundary crossing · Community of practice Inner city teaching

Reading Yuli Rahmawati and Peter Taylor's paper made me aware of my own identity as a teacher trainer and researcher and helped me to reflect on the context in which I work. At the same time, it also made me think about and how that environment is perceived by myself and by others, particularly as I work in a large university that employs and teaches students from many different countries and from the increasingly diverse and culturally rich population we have in London. In doing this, I had two responses to the paper; the first was in terms of our pre-service teacher training course and the second in terms of a research perspective on communities of practice.

"Become the teacher you want to be" is advice that I regularly give to my pre-service teachers and yet, in reading this paper, I was struck by the idea that cultural identity and experience interact and set the confines in which this may happen. So, my query was whether pre-service teachers can become the teacher they want to be. Is this a decision that these pre-service teachers bring to or take as they start the course or develop through doing the course? Is this view fixed or dynamic?

It is generally accepted that pre-service teachers come to teacher education programmes with already well-grounded beliefs about teaching and learning which are resistant to change (Pajares 1992). However, Nese Cabaroglu and Jon Roberts (2000: 392) tested this assumption with twenty students at the University of Reading, UK, and the findings revealed that, during the teacher education course, all except one student changed the way they perceived what went on in classrooms. Through engagement socially and culturally with the new environment of their teaching practice school, and through prompts and guidance provided by their tutors to research their new context, the pre-service teachers became 'generators of knowledge' (Cochrane-Smith and Lytle 1993). This led them to reinterpret the ideas about teaching and learning, gained from their own education and so understand their classroom from a new perspective. Like the University of Reading, we hope that the opportunities we offer as part of the pre-service course, provides the impetus to allow change to occur for these new recruits to the profession but, what we fail to do, is to check or analyse what effect this has on our course participants. In other words, we offer opportunity and then simply hope that this enables pre-service teachers to consider and then reconsider their initial views.

On our pre-service teacher training course, our approach is that we offer a wide range of experiences in different types of school in terms of size, demographics, provision, location and ethos, so that participants can begin to experience and so understand the many different types of school and classroom that occur in a large city. We also provide experience in informal educational settings like museums and field centres. Through these experiences and regularly questioning how and why things work within these varied institutions, we hope that the pre-service teachers will begin to see classrooms through new eyes, by comparing these new experiences in their teaching role with those of their own schooling seen through student eyes. We hope to increase the options open to them in terms of how they might teach and students might learn and to foster confidence in making choices about approaches and styles of teaching and learning. 
I began to ponder on the contexts and experiences that we present pre-service teachers with as they begin to work in schools, realizing that these may be very different to those that they experienced as a student in school. Admittedly, about one third of our trainees either grew up or studied in London for their first degree and so may have come from similar contexts to those we introduce them to, but that still leaves the majority of the cohort who may have had very different schooling to the one they have now entered in the teacher role. With any system, there are norms and expectations from those who form part of that community but also from those who enter that new community, and these may complement or clash. Our experience is that in the school system expectations are likely to revolve around anticipated student behaviour, respect for authority, attitude to work, perseverance with task and expectations in terms of examination success. Interestingly, for London schools, we buck the trend for this last category; while many cities have low examination success comparatively, London schools, on average, are performing above the national average in terms of examination results. However, when our trainee teachers come to work in London they are often surprised by the reported examination success of London schools, because they have pre-conceptions and sometimes great concerns over the possible behavioural problems that may arise in London classrooms, whether students will have good work ethics and whether they can cope with the demands of the curriculum.

We deliberately place pre-service teachers in schools that are different from the ones they attended themselves as students, and I now am starting to realise that, for many of these trainee teachers, they do experience 'culture shock' when they first go to their teacher placement school. My concern is whether, on a 12 week teaching practice, there is sufficient time for them to modify their thoughts and feelings towards that environment, as Nan Sussman (2000) suggests, or whether the time span is too short for them to interpret their new cultural environment more positively. If this is the case, then it is unlikely that a new or reframed cultural identity will emerge because there is insufficient input and experience within the 12 week teaching block to enable trainees to understand this new cultural environment.

Indeed, we find, on completing their teaching course, that some of our pre-service teachers decide early in the course to take positions in schools similar to the ones they went to as students. That is not to say that a good many pre-service teachers do not take up jobs in inner city schools, but rather that a small group of pre-service teachers, who had not been educated in an inner city environment, decide, very early in the course, to return to teach in contexts that they had been familiar with pre-course. Perhaps we need to tailor better our system so that trainees do get a different experience to that they had as school students but not so different as to prevent them making sense cognitively and emotionally of what goes on in that school. What we want is a response to their new environment, a re-interpretation of what they know and believe that has been challenged by the new context the pre-service teachers find themselves in. What we might be getting is an emotional reaction to the different context, where the pre-service teacher is so shocked by the differences they perceive, that they then become unable to see themselves as a teacher in that type of school and so seek solace in returning to an environment they know. Sue Lasky (2005: 901) describes this type of reaction using the notion of 'professional vulnerability', which seems to explain some of the tensions that teachers experience at various times in their professional lives, defining it as "a multidimensional, multifaceted emotional experience that individuals can feel in an array of contexts".

As I read this paper, I was also reminded of Etienne Wenger's work on boundary crossing and communities of practice (Wenger 1998). Glen Aikenhead (1996) and Henry 
Giroux (1992) raise the issue of interacting cultural groups, where teachers from one cultural setting step into a different cultural context and this action causes both conflict and reflection, as the teacher tries to make sense of the new system by considering both its similarities and differences with what they know. Rahmawati and Taylor state that "People can have both negative and positive experiences when they interact with other cultures that have distinctly different values, beliefs and practices". So, just as Yuli anticipated how Australian students might respond to her lessons and then was surprised when their reaction was different to what she had experienced in Jakarta, I would imagine that my trainee teachers have similar revelations, except theirs are even more surprising because, of course, they are comparing how they behaved as students with how their class now behaves with them.

Although Wenger's view explains the situations in which boundary crossing occurs, they are insufficient in explaining the meaning-making that occurs. Instead, it is perhaps better to consider the boundary crossing as a discursive and experiential space in which the context brings new meaning making to the use of familiar objects as much as it introduces new things to be made sense of. Therefore, in moving to Australia, Yuli has the opportunity to reflect and reconsider how the knowledge and practice she had previously drawn on to teach in Jakarta and so bring new meaning to these. For example, she is surprised by the student's question about whether the water produced in the chemical reaction is drinkable. The surprise is twofold: first, that students ask questions of their teachers, when, in her experience, students tended not to do this in class situations; and, secondly, she realizes that the student may not be thinking about the activity in the same way as she was. While teachers can plan activities and prepare questions as part of the lesson planning process, what is always difficult to anticipate are the responses that students may produce and how you might deal with these. This is a difficult task in a context you know well and so, in a new context, unexpected responses must seem even more daunting.

What I found particularly interesting in this paper was the interpretation and assessment of self that Yuli used to explore her identity. It comes across as both dynamic yet developing and is presented as an evolving and emerging entity for Yuli. It was almost as if she could look inwards at what her experience advised her about what she was currently perceiving, while at the same time allowing the challenge of a new setting to reinterpret that 'experienced self' within the new cultural context. While challenge and possibly conflict may play a part in this, it was clear that Yuli envisaged this from a growth aspect. I feel an important lesson for us all is to occasionally search and research that cultural journey that we have taken as we develop and sometimes question our professional selves.

Open Access This article is distributed under the terms of the Creative Commons Attribution 4.0 International License (http://creativecommons.org/licenses/by/4.0/), which permits unrestricted use, distribution, and reproduction in any medium, provided you give appropriate credit to the original author(s) and the source, provide a link to the Creative Commons license, and indicate if changes were made.

\section{References}

Aikenhead, G. S. (1996). Science education: Border crossing into the subculture of science. Science Education, 69, 453-475. doi:10.1080/03057269608560077.

Cabaroglu, N., \& Roberts, J. (2000). Development in student teachers' pre-existing beliefs during a 1-year PGCE programme. System, 28, 387-402. doi:10.1016/s0346-251x(00)00019-1. 
Cochrane-Smith, M., \& Lytle, S. L. (1993). Inside/outside: Teacher research and knowledge. New York: Teachers College. doi:10.1007/978-94-6091-403-4_3.

Giroux, H. (1992). Border crossings: Cultural workers and the politics of education. London: Routledge. doi: $10.2307 / 1315448$.

Lasky, S. (2005). A socio-cultural approach to understanding teacher identity, agency and professional vulnerability in a context of secondary school reform. Teaching and Teacher Education, 21, 899-916. doi:10.1016/j.tate.2005.06.003.

Pajares, F. (1992). Teachers' beliefs and educational research: Cleaning up a messy construct. Review of Educational Research, 62, 307-332. doi:10.3102/00346543062003307.

Sussman, N. M. (2000). The dynamic nature of cultural identity throughout cultural transitions: Why home is not so sweet. Personality and Social Psychology Review, 4, 355-373. doi:10.1207/ s15327957pspr0404_5.

Wenger, E. (1998). Communities of practice: Learning, meaning and identity. Cambridge: Cambridge University Press.

Christine Harrison is senior lecturer in science education at King's College, London, UK. Her research focuses on professional learning with both pre- and in-service teachers, where she explores how teachers conceptualise classroom assessment and its links with teaching and learning. 